\title{
Thinking fast and slow about willingness to communicate: A two-systems view
}

\author{
Peter D. MacIntyre a * (D), Lanxi Wang a (D), Gholam Hassan Khajavy b (D) \\ a Cape Breton University, Sydney, NS, B1P 6L2, Canada \\ ${ }^{b}$ University of Bojnord, Iran
}

\begin{abstract}
APA Citation:
MacIntyre, P. D., Wang, L., \& Khajavy, G. H. (2020). Thinking fast and slow about willingness to communicate: A two-systems view. Eurasian Journal of Applied Linguistics, 6(3), 443-458.
\end{abstract}

Doi: 10.32601/ejal.834681

\begin{abstract}
How does a person decide whether she or he is willing to communicate? Dual-process theories have been influential in the literature on the psychology of making judgments and decisions. Dual-process theories make a distinction between cognitive processes that are fast, automatic, and unconscious (also called 'experiential' thinking) and those that are slow, deliberative, and conscious (also called 'rational' thinking). The study assesses differences in willingness to communicate (WTC) ratings made based on rational and experiential processes, and differences between native to second language WTC. Data were collected from a sample of 84 students in Iran and 82 students in Canada. Both groups assessed their WTC using English as a second language in Iran and as a native language in the Canadian sample. Data analysis showed that a preference for using rational thinking, as measured by the Rational-Experiential Inventory (Pacini \& Epstein, 1999), was correlated with WTC ratings made fast and slow, but only in the second language. We also found WTC ratings were significantly higher when made fast compared to slow, regardless of language group. Pedagogical implications are discussed with advice to teachers how to capitalize on rational thinking and to avoid hesitation in communication.
\end{abstract}

(C) 2020 EJAL \& the Authors. Published by Eurasian Journal of Applied Linguistics (EJAL). This is an open-access article distributed under the terms and conditions of the Creative Commons Attribution license (CC BY-NC-ND) (http://creativecommons.org/licenses/by-nc-nd/4.0/).

Keywords: Willingness to communicate; pyramid model; dual process theory; cognitive-experiential self theory (CEST); Rational-Experiential Inventory (REI).

\section{Introduction}

In language-learning situations, making the choice to communicate (or not) is sometimes effortless and other times difficult; it is surprisingly complex and might be the most important type of decision a person can make regularly during the languagelearning process (MacIntyre, 2020). Language learning and communication are strongly interconnected: it has been widely accepted for a long time that one must talk in order to learn (Cao \& Philp, 2006; Skehan, 1989). The importance of communication has been also emphasized in interaction hypothesis (Long, 1996) and output hypothesis

\footnotetext{
* Corresponding author.Tel.: +1-902-563-1315

E-mail address: peter_macintyre@cbu.ca

http://dx.doi.org/10.32601/ejal.834681
} 
(Swain \& Lapkin, 1995). For both teachers and learners who are invested in the process of learning to communicate, it is important to understand how a person arrives at the decision on their willingness to communicate (WTC). Given that there is more than one way to arrive at a decision, the research reported here addresses an issue that has not yet been addressed in the literature: is it better to make the decision on WTC quickly or slowly?

\subsection{Conceptualizing WTC}

WTC was originally conceptualized as a personality trait, a stable individual difference variable. It emerged in the native-language (L1) communication literature, first as unwillingness to communicate (Burgoon, 1976) and later as a revised concept, framed more positively, as WTC (McCroskey \& Baer, 1985; McCroskey \& Richmond, 1991). McCroskey and Baer (1985) reported correlations among key variables related to WTC including communication apprehension, competence, extraversion, alienation, and anomie. Later, MacIntyre and Charos (1996) integrated the predictors of WTC into a path model providing evidence that personality was foundational to WTC, with perceptions of competence and communication apprehension as the two immediate, direct influences on WTC (in the L1). Over the past two decades, research has generally supported the idea that WTC predicts L1 communication (for a recent summary, see MacIntyre, 2020).

If WTC is relevant to L1, it may be even more relevant to communication behavior in second and foreign languages (L2), for pedagogical, social, and psychological reasons. In terms of pedagogy, WTC can be considered a primary goal of language learning students not only learn to talk in the L2, they talk in the L2 in order to learn (Cao \& Philp, 2006; Long, 1996; Skehan, 1989). MacIntyre, Clément, Dörnyei and Noels (1998) proposed that WTC is one of the most important outcomes of a language program. It serves multiple functions in the language classroom and can be studied from a microperspective, examining influencing communication at particular moments during a lesson, to a macro-perspective on the communicative results of language development (Mystowska-Wiertelak \& Pawlak, 2016, 2017). Socially, having higher levels of WTC opens the door to intergroup contact, as well as travel and career opportunities around the world (Clément, Baker, \& MacIntyre, 2003; Wen \& Clément, 2003; MacIntyre, Baker, Clément \& Conrod, 2001). Yashima (2002) found that, among Japanese learners, having 'international posture', which reflects interest in other parts of the world and an openness toward international experiences, increased WTC. Several studies have suggested higher WTC in situations allowing free choice and authentic use of the L2 outside the classroom, even in English as a Foreign Language (EFL) situations where opportunities are infrequent (Başöz \& Erten, 2018). Psychologically, factors that contribute to increasing or decreasing WTC in L1 are often even more variable in L2. Lower levels of anxiety and higher perceptions of language competence are strongly associated with WTC in both L1 (McCroskey \& Richmond, 1991) and the L2 (MacIntyre, Baker, Clément \& Donovan, 2002; Yashima, Zenuk-Nishide \& Shimizu, 2004). Metaanalysis has confirmed the important role that language anxiety and perceived 
competence, along with motivation for learning, play in generating WTC (Elahi Shirvan, Khajavy, MacIntyre, \& Taherian, 2019). In considering the important role of WTC in L2 teaching and learning, Başöz and Erten (2018, p. 84) suggest “...foreign language teacher education programs, in which the first seeds of change are sown, should lay a special emphasis upon developing communication skills of prospective EFL teachers."

To gather the variables that might be relevant to L2 WTC, MacIntyre et al., (1998) developed the 'pyramid model' of WTC (see Figure 1). The six layers of the model are organized along the lines of proximal-distal influences and breadth-of-concept. At the base of the pyramid are long-term, enduring, stable factors, while those shown at higher levels of the pyramid reflect specific situational or time-limited processes, factors that are especially relevant to L2 communication. Eventually, the combination of factors converges on a specific moment in time, when an opportunity to communicate arises. At such a moment, a decision is made and a specific behavioural intention to communicate (or not) emerges. The intention is often based on a variety of considerations, some that push individuals toward communicating and others that hold them back. Based on Kurt Lewin's theorizing, MacIntyre (2007) described the volitional choice to communicate as a continuous competition between driving forces and restraining forces, the former encouraging communication and the latter preventing it. MacIntyre went on to suggest that in general it is "easier to modify a person's actions by reducing the restraining forces than it is by increasing the driving forces" (p. 571). The interacting driving and restraining forces, or factors underlying WTC, are not necessarily combined in the same way every time because the relevancy of specific factors can change quickly, and WTC ratings can fluctuate with major or subtle changes in the communication context (MacIntyre, Burns \&, Jessome, 2011). By emphasizing WTC changes from one moment to the next in reaction to what is happening in the local context, the dynamic conceptualization of WTC differs from the ways earlier trait theory described it (Cao, 2014; Kang, 2005; MacIntyre \& Legatto, 2011).

\subsection{The process of deciding on WTC}

One of the major theoretical issues that has not yet been addressed is the question of different ways of deciding on WTC, or how a person makes the decision on how willing they are to communicate at a given moment. MacIntyre (2020) describes a self-reflective story offered by a 12-year-old female learner in an intensive French immersion program who had an opportunity to communicate with a friend of her mother at a craft show. The young learner said that she wanted to communicate, but when asked to say hello to her mother's friend in French, she did not say anything. She ended the brief narrative by saying that she would communicate if another opportunity arose. Does such a brief but complex narrative reflect a learner who is willing or unwilling to communicate? To address this question, we can focus on the process of deciding whether to talk or not. On the one hand, the trait approach to WTC examines the relative influence of longterm processes such as motivation, language competence, and levels of anxiety that a person tends to experience (Başöz \& Erten, 2018; Khajavy, Ghonsooly, Hosseini Fatemi, 
\& Choi, 2016; Khajavy, MacIntyre, \& Barabadi, 2018; Peng \& Woodrow, 2010). On the other hand, the dynamic research tradition focuses on rapid fluctuations in WTC, which implicates made decisions made quickly (MacIntyre, 2020). These two approaches mirror modern dual-processing theories (Frankish, 2010).

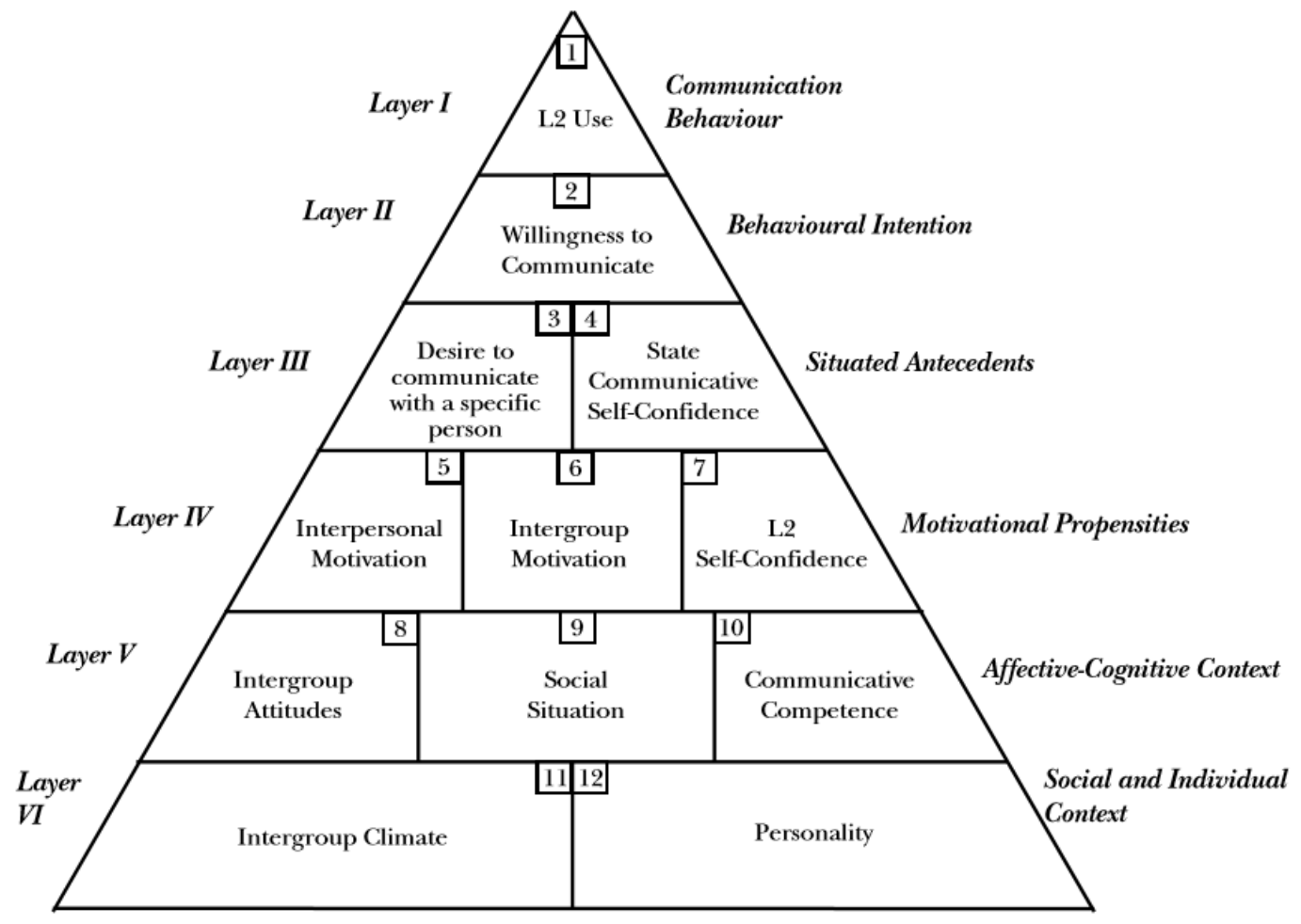

Figure 1: The pyramid model of WTC (from Macintyre et al., 1998).

Perhaps the most prominent presentation of dual-processing theories is Kahneman's (2011) best-selling book Thinking Fast and Slow. Kahneman blandly labelled the two processes System 1 and System 2 to avoid evoking unintended connotations among his readers. System 1 is rapid, intuitive, and emotional, but is error-prone because it relies on heuristic thinking to make judgements very quickly. Comparatively, System 2 is slower, logical, and conscious; it is more deliberative and effortful but is still prone to the effects of many cognitive and motivational biases. In our daily lives, we often rely on System 1 because of the need to handle a vast amount of input in complex social settings, such as walking down a city street or talking with a friend while driving a car. However, System 2 is always running and can be used for decision making whenever a person chooses to think deliberately.

Kahneman's two systems are based in part on Epstein's Cognitive-Experiential Self Theory (CEST, Kaufman, 2016). CEST (Epstein, 1991, 1994) helps to contextualize dual processing into a broader self-related system. In CEST, the two systems have characteristics similar to System 1 and System 2, called 'experiential' and 'rational', respectively. Compared to the rational system, Epstein, Pacini, Denes-Raj, and Heier (1996, p. 39) described the experiential system as "...automatic, preconscious, holistic, associationistic, primarily nonverbal, and intimately associated with affect". The 
rational system operates at the "conscious level and is intentional, analytic, primarily verbal, and relatively affect free." The experiential system favours decision making based on narratives and exemplars, focusing on specific instances as the basis for reasoning. The experiential system does not require standards of logic in decision making because it is based on experience and its conclusions are self-evident. Applied to WTC, the experiential system can return a judgement quickly, one that cannot be questioned by logic, because if a person feels good about talking or does not feel like talking at the moment, that is the end of the decision-making process. Epstein refers to these experiential judgements as "vibes" - affective reactions based on rapidly combining past experiences with current thinking and anticipated events. This process operates largely outside of the person's conscious awareness. However, if asked to explain oneself, a rational process can be activated to provide a plausible justification. "Seeking to understand their behaviour, [people] usually succeed in finding an acceptable explanation. Insofar as they can manage it without too seriously violating reality considerations, they will also find the most emotionally satisfying explanation possible" (Epstein, 2003, pp. 161-162).

Based on CEST and dual-processing theory, we might expect different WTC ratings if a learner is thinking fast versus thinking slow, using experiential versus the rational systems. Epstein and colleagues (1996) developed a scale to measure individual differences in the tendency to rely on the rational versus experiential system: the original Rational-Experiential Inventory (REI) was developed to analyze individual differences in thinking styles with subscales measuring the need for cognition and faith in intuiting. The scale was modified by Pacini and Epstein (1999) to address psychometric problems with the original scale items. The modified measure examined both the rational and experiential thinking styles in terms of ability and engagement, creating four subscales: Rational Ability, Rational Engagement, Experiential Ability, and Experiential Engagement.

In one of the few second-language acquisition studies to use the REI, Granena (2016) found evidence that its rational and experiential modes of thinking were related to different aspects of language aptitude. Granena suggested that

...different cognitive style preferences and aptitude profiles could have different advantages in language learning, for example, to learn systematically analyzing linguistic material or to learn by engaging in communicative language use (“talk to learn” approach). (p. 581)

However, we do not yet know much about the preference for rational versus experiential thinking and how it might be related to WTC ratings if they are made fast versus slow. As noted above, WTC and talking in order to learn are not necessarily straightforward decisions. For example, deliberately enrolling in a language program in order to learn to speak a new language is a deliberate decision that may differ substantially from a rapid, in-the-moment decision to talk to a specific person (see MacIntyre et al., 1998).

\subsection{The present study}


The present study examines whether thinking fast or slow is more likely to produce higher WTC ratings. We might hypothesize on the one hand that thinking slow (using the rational system) will produce relatively high ratings of WTC, especially among L2 learners who, even despite occasional reluctance to communicate, realize that talking in order to learn is required. On the other hand, ratings of WTC might be higher when thinking fast (using the experiential system) to avoid the influence of a restraining force that arises based on remembering a negative prior experience during communication. We will test these ideas in two ways, first looking for correlations between WTC and individual differences in the tendency to think fast or slow, and then looking for differences in levels of WTC ratings made fast versus slow. The specific research questions for the present study are:

1. How strongly do ratings of WTC correlate with preference for using the rational and experiential systems? We hypothesize that L2-WTC will correlate positively with scores reflecting rational thinking.

2. Does thinking fast or slow tend to produce higher WTC ratings, and does language (L1 vs L2) make a difference? This will be tested with a 2x2 Split Plot ANOVA comparing WTC ratings made fast vs slow for L1 vs L2 speakers.

\section{Method}

\subsection{Participants}

Participants of the current study included two groups of students $(N=166)$, one group in Canada $(N=82)$ and the other in Iran $(N=84)$. The Canadian sample included 55 females, 26 males, and one whose gender was unspecified. The Canadian group ranged in age from 17 to 37 , with a mean age of $19.87(S D=3.21)$. Participants in this group spoke English as their L1. The Iranian sample included 59 females and 25 males; these participants spoke English as an L2. The Iranian group ranged in age from 14 to 31 , with a mean age of $20.88(S D=2.43)$. Canadian participants all were university students. Iranian participants were both university students who were studying Teaching as a Foreign Language and English language learners who were learning English at private language institutes. Participants self-rated their proficiency levels as Beginner $(\mathrm{N}=6)$, Low Intermediate $(\mathrm{N}=5)$, Intermediate $(\mathrm{N}=34)$, High Intermediate $(\mathrm{N}=34)$, and Advanced $(\mathrm{N}=4)$." One person did not respond to this item.

\subsection{Measures}

The Willingness to Communicate (WTC) scale. The current study employed the WTC scale developed by McCroskey and Baer (1985) to measure trait- or personality-like WTC. The scale measures a variety of instances where one might be confronted with the decision to communicate or not, including items about four main communication contexts (public speaking, talking in meetings, talking in small groups, and talking in dyads) combined with three main receiver types (strangers, acquaintances, and friends) to create 12 items. Examples of the items include "present a speech to a group of 
strangers" and "talk with a friend while standing in line". The scale included three additional items that were scored (talk with a secretary, a waiter/waitress, and a salesperson in a store) for a total of 15 items. Respondents indicate the percentage of time they would choose to communicate in each context $(0=$ never; $100=$ always $)$. Reliability testing in McCroskey and Baer's (1985) study using 428 college students as participants showed very good internal consistency for the total WTC scale (Cronbach's alpha $=0.92)$.

The present study adapted the scale into two versions. The WTC-fast scale measured participants' WTC when asked to respond quickly. Participants indicated whether they would choose to communicate in each type of situation by selecting "yes" (scored as 1) or "no" (scored as 0) accordingly. A total score was computed for each person, minimum value $=0$, maximum value $=15$. Participants were encouraged to respond as fast as they could; they were asked to report the total number of seconds they used to answer these questions. Those who used more than 60 seconds to respond were excluded from the study. The 15-item total WTC-fast score was computed by adding the times they responded "yes". Its reliability was acceptable, with internal consistency coefficients of .80 and .72 for the Canadian and Iranian contexts, respectively.

The 15-item WTC-slow scale measured participants' WTC when asked to respond slowly with reflection. Participants wrote down reasons to start or not to start a conversation in each situation and indicated the percentage of time they would choose to communicate $(0 \%=$ never; $100 \%=$ always $)$. The WTC-slow score was computed for each person by averaging the percentages for the items and dividing the total by 100 , then multiplying by 15 to create a scale score comparable to the fast measure (with a possible range of 0 to 15). The WTC-slow scale showed good reliability, with internal consistency coefficients of .88 and .87 for the Canadian and Iranian contexts, respectively.

The Rational-Experiential Inventory (REI). The REI is composed of two subscales: rationality and experientiality, each with 20 items. The rationality scale reflected cognitive processes that are slow, rational, and analytical. Examples of the items on this scale included "I prefer complex problems to simple problems" and "I usually have clear, explainable reasons for my decisions". In contrast, the experiential scale represented cognitive processes that are fast, emotional, and intuitive. Examples of items on this scale included "I trust my initial feelings about people" and "I tend to use my heart as a guide for my actions". Respondents rated all items on a 5-point Likertscale that ranged from 1 (definitely not true of myself) to 5 (definitely true of myself). The reliability ( 0.90 and 0.87 for Rationality and Experientiality, respectively) and validity of the new REI were supported by Pacini and Epstein (1999). In the current study, both Rationality (with internal consistency coefficients of .87 and .82) and Experientiality (with internal consistency coefficients of.87 and .89) showed good reliability for the Canadian and Iranian contexts.

Self-Reported L2 Proficiency Level. To gauge Iranian respondents' level of perceived L2 proficiency, a single item was used: "If English is not your first language, how would 
you describe yourself in English, Beginner, Low Intermediate, Intermediate, High Intermediate, and Advanced."

\subsection{Procedure}

After providing informed consent, students participated in a testing session during which the two WTC scales, the REI, and a demographic information sheet were distributed. WTC was assessed in two different ways, once very quickly and again slowly in a counter-balanced order (i.e., half of the respondents responded first to the slow version and half responded to the fast version). In the Iranian context, all participants were asked to answer to the questionnaire during the regular classroom hours. It should be noted that the questionnaire was translated into Persian to increase the return rate and to avoid any ambiguities and misunderstandings. Back-translation procedure, in which the original items are translated into Persian and then the Persian items are translated into English by another translator, was used to assure the accurate translation of the scales.

\subsection{Data analysis}

The current study aimed to examine correlations between two WTC measures and the REI scale were computed to examine the relationships between fast- and slow-WTC and individual differences in thinking styles. A second analysis compares WTC ratings made fast and slow among two groups of participants. In this case, a Split Plot ANOVA was used to test the effect of language group (English as L1 vs. English as L2) and responding style (fast vs. slow) on scores for the WTC measures.

\section{Results}

\subsection{Correlation analysis}

Prior to computing the correlations, we conducted two separate factor analyses on the REI scale items of both the Canadian and Iranian contexts. Results of factor analysis with direct oblimin rotation indicated a two-factor solution for both contexts, similar to the results reported by Pacini \& Epstein (1999) and by Marks, Hine, Blore, and Philips (2008). Therefore, we labelled the factors as Rational and Experiential (see Appendix for factor loadings).

Correlations were computed to investigate the relationships between fast- and slowWTC and rational-experiential thinking styles. Total scores were computed for Rational and Experiential items separately, and correlations were computed between these scales and fast- and slow-WTC ratings for both the L1 and 12 contexts (see Table 1). 
Table 1: Correlation matrix for the Canadian (L1) and Iranian (L2) contexts.

\begin{tabular}{|c|c|c|c|c|c|c|c|c|}
\hline & \multicolumn{2}{|c|}{ Slow-WTC } & \multicolumn{2}{|c|}{ Fast-WTC } & \multicolumn{2}{|c|}{ Rationality } & \multicolumn{2}{|c|}{ Experientiality } \\
\hline & L1 & $\mathrm{L} 2$ & $\mathrm{~L} 1$ & $\mathrm{~L} 2$ & $\mathrm{~L} 1$ & L2 & L1 & $\mathrm{L} 2$ \\
\hline 1- Slow-WTC & - & & & & & & & \\
\hline 2- Fast-WTC & $.75^{\#}$ & $.59^{\#}$ & & & & & & \\
\hline 3- Rationality & .15 & $.22^{*}$ & .12 & $.27^{*}$ & & & & \\
\hline 4- Experientiality & .08 & -.20 & .04 & .14 & .10 & .01 & & \\
\hline 5-L2 Level & - & $.28^{*}$ & - & $.37 \#$ & - & .20 & - & -.14 \\
\hline
\end{tabular}

For the Canadian group (L1), results showed significant positive correlation between fast- and slow-WTC, $r=.75, p<.001$. The shared variance $\left(r^{2}\right)$ was $56 \%$. However, Rationality was not significantly correlated with either fast- $(r=.12, p=.29)$ nor slowWTC $(r=.15, p=.17)$. Similarly, Experientiality was not significantly correlated with either fast- $(r=.04, p=.73)$ nor slow-WTC $(r=.08, p=.47)$. Furthermore, there was no significant correlation between Rationality and Experientiality, $r=.10, p=.37$.

In the Iranian group (L2), results also showed significant positive correlation between fast- and slow-WTC, $r=.59, p<.001$. The shared variance $\left(r^{2}\right)$ was $35 \%$. Rationality correlated significantly with both fast- $(r=.27, p=.01)$ and slow-WTC $(r=$ $.22, p=.04)$, indicating that students who showed more preference for rational thinking experienced higher levels of WTC. Experientiality was not significantly correlated with either fast- $(r=-.14, p=.20)$ nor slow-WTC $(r=-.20, p=.07)$. Similar to the Canadian group, Rationality was not significantly correlated with Experientiality in the L2 group, $r=.01, p=.92$. Additionally, perceived level of English proficiency significantly correlated with both fast- $(\mathrm{r}=.37, \mathrm{p}<.001)$ and slow-WTC $(\mathrm{r}=.28, \mathrm{p}=.01)$, which indicates that L2 learners who perceived themselves as more proficient tended to report higher WTC.

\subsection{Fast vs Slow in L1 vs L2}

A $2 \times 2$ Split Plot ANOVA was conducted to test the effect of language group (L1 vs L2) and responding style (fast vs slow) on WTC scores. Prior to conducting the test, the assumption of homogeneity of variance for fast-WTC was tested and satisfied by Levene's test, Levene's $F(1,159)=.04, p=.83$, as well as for slow-WTC, Levene's $F(1$, $159)=3.56, p=.06$. Results indicated a significant main effect of responding style, $F$ $(1,159)=30.79, p<.001$, partial $\eta^{2}=.16$. Participants' WTC scores were higher when rated fast $(M=10.20)$ than when rated slow $(M=9.16)$. The main effect of language group was not significant, $F(1,159)=1.48, p=.23$, partial $\eta^{2}=.01$. WTC scores were similar between participants who spoke English as L1 in Canada $(M=9.93)$ and those who spoke English as L2 in Iran $(M=9.43)$. Further, the interaction of language group and responding style on WTC was found to be nonsignificant, $F(1,159)=.01, p=.91$, partial $\eta^{2}=0$. 
Although the interaction is not significant, to focus the analysis on the thinking fast vs slow in the different language groups, two post-hoc dependent $t$-tests were conducted. We compared WTC scores rated fast versus slow in the Canadian and the Iranian group separately. The mean WTC-fast score of the Canadian group was 10.45 $(S D=3.01)$, whereas the mean WTC-slow score was $9.39(S D=2.39)$. This difference was significant $t(81)=4.80, p<.001$, Cohen's $\mathrm{d}=.53$. The mean WTC-fast score of the Iranian group was $10.01(S D=2.94)$, whereas the mean WTC-slow score was $9.01(S D$ $=3.06)$, which were also significantly different, $t(83)=3.39, p<.001$, Cohen's $\mathrm{d}=.37$.

\section{Discussion}

At first glance, the results of the correlation analysis and the ANOVA might seem contradictory. However, the questions addressed by the two analyses are different, and the results have different implications for language teaching. On the one hand, the positive correlation between rational scores and L2-WTC ratings shows that the more learners prefer rational thinking, the more they seem to endorse willingness to talk (in order to learn a new language). Being willing to communicate makes sense as a learning strategy, especially if one must seek out opportunities for L2 use (Başöz \& Erten, 2018). However, when asked to make a decision about talking in a specific type of situation, as reflected in WTC scale items such as presenting a talk to a group of strangers or talking with a small group of friends, additional driving and restraining factors may come to mind. These additional factors make the WTC decision more complex, and when they are integrated quickly, they may be responsible for differentiating ratings made fast versus slow.

The answer to the first research question tested here suggests that a preference for thinking slow will be associated with relatively high ratings of WTC, especially among L2 learners. The significant positive correlations between Rationality and L2 WTC scores support this prediction. If thinking about talking in order to learn is required in the L2, but not the L1, the pattern of correlations makes sense. Communicating in L2, or any additional language, is more complex than using the L1 wherein more elements of the communication process can be taken for granted (MacIntyre, 2020). Using an L2 often carries additional social, cultural, and even political considerations that are irrelevant to L1 use (MacIntyre et al., 1998; Wen \& Clément, 2003). As active language learners, a deliberate, analytic thinking style seems to be associated with increased L2 WTC both when the WTC rating is made quickly and when made more slowly. Further, the lack of correlation with Experiential scores suggests that WTC scores are not consistently related to the tendency to rely on what Epstein (2003) called unconscious vibes in either L1 or L2. That is not to say that vibes are irrelevant in a communication situation, but in the present study we asked respondents to think about communicating in various situations. Future research would be required to assess the role of unconscious vibes in decision making during communication in situ.

The results of the ANOVA for the second research question shows that, when comparing mean ratings in an ANOVA, thinking fast tends to produce higher WTC 
ratings than thinking slow, a pattern that holds across both L1 and L2 groups. This is encouraging because it shows the processes underlying fast and slow WTC judgements may be similar despite differences in language contexts, English-L1-Canada vs English-L2-Iran. We cannot assume that WTC will always be higher in the L1 than the L2; indeed, the present data show that they can be comparable. Making judgements about WTC is a complex process implicating interaction among a long list of factors.

The answers to the questions posed by the present study are especially relevant to language teachers. Results suggest that if the goal of an L2 teacher is to increase WTC, we would advise teachers to encourage students to use the rational system to generate WTC as an intention to communicate when an opportunity arises, then to think fast when such an opportunity comes along. A preference for thinking using the rational system is correlated with higher WTC in the L2 only, suggesting that prospective speakers might benefit from thinking through the benefits of L2 communication. However, when responding to the WTC items to tell us how willing they are to communicate, slower deliberations over whether to speak or not seem to be associated with generally lower WTC scores in both L1 and L2. In theory, this pattern might arise if the results of those deliberations produce activation of restraining forces (MacIntyre, 2007). Başöz and Erten (2019, p. 14-15) emphasized that “...L2 communication primarily takes place in the classroom in the EFL settings like Turkey, it is crucial for EFL teachers to foster facilitating factors of L2 WTC as much as possible in the classroom". Therefore, it is crucial that teachers provide a supportive classroom environment that improves WTC in EFL contexts (Khajavy et al., 2018).

The suggestion we offer learners, based on the data here, is to jump right in when an opportunity to communicate arises. Hesitation in communication is problematic for several reasons. First, the nature of communication is exquisitely timed. The old adage 'he who hesitates is lost' is well applied to communication opportunities. Hesitations as brief as a half-second may preclude a person from turn-taking or talking at all. Second, the initial vibe or feeling toward communication, if positive, can be lost if a search through memory reveals that there is a risk or potential for a prior negative experience to repeat itself. Third, communication is an intrinsically motivating activity and therefore the driving forces that push us toward communicating with other people can be very strong (MacIntyre et al., 1998). However, these driving forces are often met by restraining forces that may lead people to be quiet and avoid communication. In language-learning contexts, activation of these restraining forces can potentially have a dramatic effect on the learning outcomes. Epstein's (1991; 2003) Cognitive Experiential Self Theory suggests that these decision-making processes happen very quickly and outside of our conscious awareness. To some extent, teachers can take advantage of this process by encouraging students to think fast and act quickly on positive vibes. It might be especially important for teachers to identify students who tend to think too much before talking. The results of this study suggest that thinking fast can facilitate WTC. However, teachers should be very careful with hesitant or anxious L2 learners so as not to generate negative experiences or create "bad vibes", and try to explain to learners how to integrate rational thinking about finding 
appropriate communication opportunities and then jumping into them without too much hesitation or over-thinking.

There are several limitations of this study to consider. The first limitation concerns the reliance on self-report questionnaires to measure our variables. Qualitative research, including interviews and observations, can add insight into the complex processes underlying WTC judgements. In addition, a self-report questionnaire takes time to complete, even in the fast context used here where a one-minute time limit was imposed. Although it is possible to make WTC judgements more rapidly and continuously (MacIntyre \& Legatto, 2011), such a procedure cannot use the multi-item scales that prior WTC research used. In addition, the L1-L2 distinction described above is confounded with differences in context between Canada and Iran. Ideally, L1 and L2 would be assessed in both locations, and among a diverse group of learners with different levels of L2 experience allowing for a more robust test. This study should be viewed as preliminary and additional investigations of these research questions, across multiple contexts, are encouraged.

\section{Conclusions}

In conclusion, dual-processing theories such as Khanaman's (2011) System 1 and System 2, or Epstein's (2003) CEST, can be meaningfully applied to communication situations. Prior research has suggested that there are differences between L1 and L2 in how a speaker might decide how willing they are to communicate, and we see here that a preference for rational thinking is associated with higher L2 WTC. Yet, there are similarities across languages as well, and it would appear that thinking fast is associated generally with higher WTC.

\section{Acknowledgements}

We would like to thank the research participants for their time in completing the study.

\section{The Research and Publication Ethics Statement}

The Ethics Committee/Board approval for this study was obtained from Cape Breton University Research Ethics Board in July, 2018, protocol number 181-164. No ethical considerations were violated in this study.

\section{The Conflict of Interest Statement}

In line with the statement of Committee on Publication Ethics (COPE), I/we hereby declare that I/we had no conflicting interests regarding any parties of this study. This research study is funded in part by the Social Sciences and Humanities research Council of Canada (Grant No. 435-2013-1944) without any occurrence of conflicting interest in the manner of author(s). 


\section{References}

Basöz, T, \& Erten, I. H. (2018). Investigating tertiary level EFL learners' willingness to communicate in English. English Language Teaching, 11(3), 78-87. doi:10.5539/elt.v11n3p78

Basöz, T, \& Erten, I. H. (2019). A qualitative inquiry into the factors influencing EFL learners' in-class Willingness to Communicate in English. Novitas-ROYAL, 13(1), 1-18.

Burgoon, J. K. (1976). The unwillingness-to-communicate scale: Development and validation. Communication Monographs, 43, 60-69. doi:10.1080/03637757609375916

Cao, Y. (2014). A sociocognitive perspective on second language classroom willingness to communicate. TESOL Quarterly, 48, 789-814. doi:10.1002/tesq.155

Cao, Y., \& Philp, J. (2006). Interactional context and willingness to communicate: A comparison of behavior in whole class, group and dyadic interaction. System, 34(4), 480-493. doi:10.1016/j.system.2006.05.002

Clément, R., Baker, S. C., \& MacIntyre, P. D. (2003). Willingness to communicate in a second language: The effects of context, norms, and vitality. Journal of language and social psychology, 22, 190-209. doi:10.1177/0261927X03022002003

Elahi Shirvan, M., Khajavy, G. H., MacIntyre, P. D., Taherian, T. (2019). A meta-analysis of L2 willingness to communicate and its three high-evidence correlates. Journal of Psycholinguistic Research, 48, 1241-1267. doi:10.1007/s10936-019-09656-9

Epstein, S. (1991). Cognitive-experiential self-theory: An integrative theory of personality. In R. C. Curtis (Ed.), The relational self: Theoretical convergences in psychoanalysis and social psychology (pp. 111-137). New York: Guilford Press.

Epstein, S. (1994). Integration of the cognitive and the psychodynamic unconscious. American Psychologist, 49, 709-724. doi:10.1037//0003-066X.49.8.709

Epstein, S. (2003). Cognitive-experiential self-theory of personality, In T. Millon \& M. J. Lerner (Eds.), Comprehensive handbook of psychology, Vol. 5, Personality and Social Psychology (pp. 159-184). Hoboken, NJ: Wiley.

Epstein, S., Pacini, R., Denes-Raj, V., \& Heier, H. (1996). Individual differences in intuitiveexperiential and analytical-rational thinking styles. Journal of Personality and Social Psychology, 71(2), 390. doi:10.1037/0022-3514.71.2.390

Frankish, K. (2010). Dual-process and dual-system theories of reasoning. Philosophy Compass, 5, 914-926. doi:10.1111/j.1747-9991.2010.00330.x

Granena, G. (2016). Cognitive aptitudes for implicit and explicit learning and informationprocessing styles: An individual differences study. Applied Psycholinguistics, 37(3), 577-600. doi:10.1017/S0142716415000120

Kahneman, D. (2011). Thinking, fast and slow. CA: Anchor Canada.

Kang, S. (2005). Dynamic emergence of situational willingness to communicate in a second language. System, 33, 277-292. doi:10.1016/j.system.2004.10.004

Kaufman, S. B. (2016). An ode to Seymour Epstein, originator of modern dual-process theory (1925-2016). Retrieved from https://blogs.scientificamerican.com/beautiful-minds/an-ode-toseymour-epstein-originator-of-modern-dual-process-theory-1925-2016/

Khajavy, G. H., Ghonsooly, B., Hosseini Fatemi, A., \& Choi, C. W. (2016). Willingness to communicate in English: A microsystem model in the Iranian EFL classroom context. TESOL Quarterly, 50(1), 154-180. doi:10.1002/tesq.204

Khajavy, G. H., MacIntyre, P. D., \& Barabadi, E. (2018). Role of the emotions and classroom environment in willingness to communicate: Applying doubly latent multilevel analysis in second language acquisition research. Studies in Second Language Acquisition, 40(3), 605624. doi:10.1017/S0272263117000304 
Long, M. H. (1996). The role of the linguistic environment in second language acquisition. In W. C. Ritchie, \& T. K. Bhatia (Eds.), Handbook of second language acquisition (pp. 413-468). New York: Academic Press.

MacIntyre, P. D. (2007). Willingness to communicate in the second language: Understanding the decision to speak as a volitional process. Modern Language Journal, 91, 564-576. doi:10.1111/j.1540-4781.2007.00623.x

MacIntyre, P. D. (2020). Expanding the Theoretical Base for the Dynamics of Willingness to Communicate. Studies in Second Language Learning and Teaching, 10, 111-131. doi:10.14746/ssllt.2020.10.1.6

MacIntyre, P. D. \& Charos, C. (1996). Personality, attitudes, and affect as predictors of second language communication. Journal of Language and Social Psychology, 15, 3-26. doi:10.1177/0261927X960151001

MacIntyre, P. D. \& Legatto, J. J. (2011). A dynamic system approach to willingness to communicate: Developing an idiodynamic method to capture rapidly changing affect. Applied Linguistics, 32, 149-171. doi:10.1093/applin/amq037

MacIntyre, P. D., Burns, C., \& Jessome, A. (2011). Ambivalence about communicating in a second language: A qualitative study of French immersion students' willingness to communicate. The Modern Language Journal, 95, 81-96. doi:10.1111/j.15404781.2010.01141.x

MacIntyre, P. D., Baker, S. C., Clément, R., \& Conrod, S. (2001). Willingness to communicate, social support, and language-learning orientations of immersion students. Studies in Second Language Acquisition, 23, 369-388. doi:10.1017/S0272263101003035

MacIntyre, P.D., Baker, S.C., Clément, R., \& Donovan, L.A. (2002). Sex and age effects on willingness to communicate, anxiety, perceived competence, and L2 motivation among junior high school French immersion students. Language Learning, 52(3), 537-564. doi:10.1111/1467-9922.00194

MacIntyre, P. D., Clément, R., Dörnyei, Z., \& Noels, K. A. (1998). Conceptualizing willingness to communicate in a L2: A situational model of L2 confidence and affiliation. The Modern Language Journal, 82, 545-562. doi:10.1111/j.1540-4781.1998.tb05543.x

Marks, A.D.G., Hine, D.W., Blore, R.L., Phillips, W.J. (2008). Assessing individual differences in adolescents' preference for rational and experiential cognition. Personality and Individual Differences, 44 (1), 42-52. doi:10.1016/j.paid.2007.07.006.

McCroskey, J. C. \& Baer, J. E. (1985). Willingness to communicate: The construct and its measurement. Paper presented at the annual convention of the Speech Communication Association, Denver, CO.

McCroskey, J. C. \& Richmond, V. P. (1991). Willingness to communicate: A cognitive view. In M. Booth-Butterfield (Ed.), Communication, cognition, and anxiety (pp. 19-37). Newbury Park, CA: Sage.

Mystkowska-Wiertelak, A. \& Pawlak, M. (2016). Designing a tool for measuring the interrelationships between L2 WTC and confidence, beliefs, motivation, and context. In M. Pawlak (Ed.), Classroom-oriented research (pp. 19-37). Heidelberg: Springer.

Mystkowska-Wiertelak, A. \& Pawlak, M. (2017). Willingness to communicate in instructed second language acquisition: Combining a macro- and micro-perspective. Bristol, UK: Multilingual Matters.

Pacini, R., \& Epstein, S. (1999). The relation of rational and experiential information processing styles to personality, basic beliefs, and the ratio-bias problem. Journal of Personality and Social Psychology, 76, 972-987. doi:10.1037/0022-3514.76.6.972

Peng, J.-E., \& Woodrow, L. (2010). Willingness to communicate in English: A model in Chinese EFL classroom context. Language Learning, 60, 834-876. doi:10.1111/j.14679922.2010.00576.x 
Skehan, P. (1989). Individual differences in second language learning. London: Edward Arnold.

Swain, M., \& Lapkin, S. (1995). Problems in output and the cognitive processes they generate: A step towards second language learning. Applied linguistics, 16(3), 371-391. doi:10.1093/applin/16.3.371

Wen, W. P., \& Clément, R. (2003). A Chinese conceptualization of willingness to communicate in ESL. Language, Culture and Curriculum, 16, 18-38. doi:10.1080/07908310308666654

Yashima, T. (2002). Willingness to communicate in a second language: The Japanese EFL context. Modern Language Journal, 86(1), 54-66. doi:10.1111/1540-4781.00136

Yashima, T., Zenuk - Nishide, L., \& Shimizu, K. (2004). The influence of attitudes and affect on willingness to communicate and second language communication. Language Learning, 54, 119-152. doi:10.1111/j.1467-9922.2004.00250.x

\section{Appendix A.}

Factor Loadings for REI items

\begin{tabular}{|c|c|c|c|}
\hline Item & Factor 1 & Factor 2 & Uniqueness \\
\hline EA1 & 0.705 & & 0.474 \\
\hline EA10c & & 0.448 & 0.741 \\
\hline EA2 & 0.401 & & 0.799 \\
\hline EA3 & 0.576 & . & 0.615 \\
\hline EA4 & 0.480 & . & 0.731 \\
\hline EA5 & 0.563 & . & 0.682 \\
\hline EA6 & 0.743 & . & 0.428 \\
\hline EA7c & -0.650 & . & 0.502 \\
\hline EA8c & -0.739 & . & 0.439 \\
\hline EA9c & . & . & 0.979 \\
\hline EE1 & 0.609 & . & 0.622 \\
\hline EE10 & 0.446 & . & 0.775 \\
\hline EE2c & -0.563 & . & 0.611 \\
\hline EE3 & 0.663 & . & 0.560 \\
\hline $\mathrm{EE} 4 \mathrm{c}$ & -0.354 & . & 0.820 \\
\hline EE5c & -0.520 & . & 0.729 \\
\hline EE6c & -0.475 & . & 0.749 \\
\hline EE7 & 0.459 & . & 0.750 \\
\hline EE8 & 0.644 & . & 0.545 \\
\hline EE9c & -0.449 & . & 0.786 \\
\hline RA1 & . & -0.427 & 0.817 \\
\hline RA10c & . & 0.621 & 0.588 \\
\hline RA2c & . & & 0.953 \\
\hline RA3c & . & 0.346 & 0.868 \\
\hline RA4 & . & -0.462 & 0.785 \\
\hline
\end{tabular}


458 MacIntyre, Wang, \& Khajavy/Eurasian Journal of Applied Linguistics, 6(3) (2020) 443-458

Factor Loadings for REI items

\begin{tabular}{lccc}
\hline Item & Factor 1 & Factor 2 & Uniqueness \\
\hline RA5 & $\cdot$ & -0.455 & 0.793 \\
RA6 & $\cdot$ & -0.409 & 0.830 \\
RA7c & $\cdot$ & 0.656 & 0.558 \\
RA8c &. & 0.445 & 0.791 \\
RA9 &. & -0.427 & 0.798 \\
RE1 &. & -0.349 & 0.868 \\
RE10 &. & -0.680 & 0.538 \\
RE2c &. & 0.582 & 0.660 \\
RE3c &. & 0.397 & 0.841 \\
RE4c & $\cdot$ & 0.546 & 0.682 \\
RE5 & $\cdot$ & -0.380 & 0.849 \\
RE6 &. & -0.592 & 0.649 \\
RE7 &. &. & 0.920 \\
RE8c &. & 0.623 & 0.600 \\
RE9c &. & 0.499 & 0.738 \\
& & & \\
\hline
\end{tabular}

Note. Rotation method is oblimin.

Factor Correlations

\begin{tabular}{lrc}
\hline & Factor 1 & Factor 2 \\
\hline Factor 1 & 1.000 & \\
Factor 2 & -0.023 & 1.000 \\
& & \\
\hline
\end{tabular}

\section{Copyrights}

Copyright for this article is retained by the author(s), with first publication rights granted to the Journal. This is an open-access article distributed under the terms and conditions of the Creative Commons Attribution license (CC BY-NC-ND) (http://creativecommons.org/licenses/by-nc-nd/4.0/). 